\title{
Aprendre a aprendre: una experiència amb la funcionalitat Wiki i l'eina taller del Moodle
}

\author{
Learning to learn: an experience with the Wiki activity and the \\ Workshop tool in Moodle \\ Aprender a aprender: una experiencia con la funcionalidad Wiki y la \\ herramienta taller de Moodle
}

\author{
Laia Lluch Molins*, Marina Solé Català** \\ *Departament de Didàctica i Organització Educativa, Facultat d'Educació \\ Universitat de Barcelona \\ Passeig de la Vall d'Hebron, 171, 08035 Barcelona \\ **Departament d'Economia, Facultat d'Economia i Empresa \\ Universitat de Barcelona \\ Av. Diagonal, 69008034 Barcelona \\ laia.1luch@ub.edu marinasole@ub.edu
}

\begin{abstract}
Resum
Estimular i promoure l'aprenentatge autoregulat, el treball autònom i la competència d'aprendre a aprendre és un dels grans reptes de l'educació superior. El feedback entre iguals pot constituir una estratègia que contribueixi a l'autoregulació, però això requereix dissenys pedagògics que permetin als estudiants participar i comprendre com millorar els seus processos d'aprenentatge. En aquest sentit, es considera que l'ús d'estratègies com l'aprenentatge cooperatiu per part del mateix estudiant pot donar suport als processos d'aprenentatge a la llum d'aquests reptes.

El propòsit de l'article és presentar dues activitats d'avaluació continuada que es van proposar als estudiants que van cursar l'assignatura Economia Política en un grup del grau de Gestió i Administració Pública (Facultat de Dret, Universitat de Barcelona) en el curs 2020-2021. Aquestes activitats van ser dissenyades en el marc del projecte I+D "Anàlisi dels efectes de la provisió de feedback suportat per les tecnologies digitals de monitorització sobre les competències transversals" (ref. PID2019-104285GB-I00). Es tractava de crear un entorn d'aprenentatge en què els estudiants haguessin de treballar cooperativament, d'una banda, i donar-se feedback els uns als altres per aconseguir millorar els resultats assolits, de l'altra.
\end{abstract}

En l'article s'introdueix, en primer lloc, un resum d'algunes aportacions teòriques rellevants relacionades amb els beneficis del feedback en les dinàmiques d'aprenentatge. A continuació es dona informació detallada sobre el disseny de l'activitat i sobre les eines tecnològiques utilitzades i els materials de suport que es van elaborar per guiar l'alumnat que va participar en l'experiència. Finalment s'aporten algunes reflexions sobre el desenvolupament i els resultats de l'experiència segons les oportunitats i limitacions trobades durant la seva implementació.

Paraules clau: Aprenentatge cooperatiu, Competència d'aprendre a aprendre, Disseny pedagògic, Educació superior, Feedback entre iguals, Gestió i administració pública.

\begin{abstract}
To stimulate and to promote self-regulated learning, autonomous learning, and learning-to-learn competence is one of the great challenges of higher education. Peer feedback can be a strategy that contributes to self-regulation, but this requires pedagogical designs that allow students to participate and understand how to improve their learning processes. It is considered that the use of strategies such as cooperative learning by the student himself can support the learning processes.
\end{abstract}


The purpose of the contribution is to present two formative assessment activities that were proposed to students of Political Economy in one group of the degree of Management and Public Administration (Faculty of Law, University of Barcelona) in the 2020-2021 academic year. These activities were designed within the framework of the R\&D project "Analysis of the effects of the provision of feedback supported by digital monitoring technologies on transversal competencies" (ref. PID2019-104285GB-I00). These activities aimed to create a learning environment in which students had to work cooperatively, on the one hand, and provide peer feedback in order to improve the quality of their task, on the other.

First of all, this paper introduces some relevant theoretical contributions related to the benefits of feedback on learning processes. Secondly, it gives detailed information about the design of these activities, with the technological tools used and the support materials that were developed to guide the students who participated in this experience. To conclude, some reflections on the development and results of the experience are provided according to the opportunities and limitations found during its implementation.

Keywords: Cooperative learning, Higher education, Learning-to-learn competence, Management and public administration, Pedagogical design, Peer feedback.

\section{Resumen}

Estimular y promover el aprendizaje autorregulado, el trabajo autónomo y la competencia de aprender a aprender es uno de los grandes retos de la educación superior. El feedback entre iguales puede constituir una estrategia que contribuya a la autorregulación, pero esto requiere diseños pedagógicos que permitan a los estudiantes participar y comprender cómo mejorar sus procesos de aprendizaje. En este sentido, se considera que el uso de estrategias como el aprendizaje cooperativo por parte del propio estudiante puede apoyar los procesos de aprendizaje a la luz de estos retos.

El propósito del artículo es presentar dos actividades de evaluación continua que se propusieron a los estudiantes que cursaron la asignatura Economía Política en un grupo del grado de Gestión y Administración Pública (Facultad de Derecho, Universidad de Barcelona) en el curso 2020-2021. Estas actividades fueron diseñadas en el marco del proyecto I+D “Análisis de los efectos de la provisión de feedback soportado por las tecnologías digitales de monitorización sobre las competencias transversales" (ref. PID2019-104285GB-I00). Se trataba de crear un entorno de aprendizaje en el que los estudiantes tuvieran que trabajar cooperativamente, por un lado, y darse feedback unos a otros para conseguir mejorar los resultados alcanzados, por otro.

En el artículo se introduce, en primer lugar, un resumen de algunas aportaciones teóricas relevantes relacionadas con los beneficios del feedback en las dinámicas de aprendizaje. A continuación, se da información detallada sobre el diseño de la actividad y sobre las herramientas tecnológicas utilizadas y los materiales de soporte que se elaboraron para guiar al alumnado que participó en la experiencia. Finalmente, se aportan algunas reflexiones sobre el desarrollo y los resultados de la experiencia según las oportunidades y limitaciones encontradas durante su implementación.

Palabras clave: Aprendizaje cooperativo, Competencia de aprender a aprender, Diseño pedagógico, Educación superior, Feedback entre iguales, Gestión y administración pública.

\section{El feedback sostenible i el treball cooperatiu per facilitar l'autoregulació de l'aprenentatge}

En el marc del projecte I+D "Anàlisi dels efectes de la provisió de feedback suportat per les tecnologies digitals de monitorització sobre les competències transversals" (e-FeedSkill), es proposa dissenyar una seqüència didàctica d'una tasca complexa objecte de peer feedback (retroacció entre iguals) suportada pel que es coneix com a tecnologia Learning Management System (LMS), per promoure l'autoregulació de l'aprenentatge i l'aprenentatge autònom. Alhora, aquest projecte es proposa analitzar el paper mediador de la tecnologia en aquests processos i com pot contribuir al desenvolupament de l'aprenentatge cooperatiu per part de l'alumnat. 
Malgrat que els ocupadors reconeixen de manera inequívoca el valor de les competències transversals o soft skills (com es posa de manifest en els informes dels ocupadors que publica AQU), vint anys després de la Declaració de Bolonya encara hi ha part del professorat universitari que es mostra escèptic respecte d'aquestes competències $\mathrm{i}$ que, si bé treballa per fomentar competències específiques, potser no té tan presents competències transversals, com ara el treball en equip i la capacitat d'aprenentatge $\mathrm{i}$ responsabilitat. ${ }^{1}$

De fet, la crisi sanitària provocada per la COVID-19 ha posat de manifest la importància de comptar amb competències transversals. En un context de docència no presencial (síncrona o asíncrona), o fins i tot de docència híbrida o mixta, el professorat ha hagut de dissenyar tasques d'aprenentatge i avaluació adaptades a la lògica de l'ensenyament en línia, anant més enllà de la mera adaptació del que venia fent presencialment. Quant a les sessions expositives síncrones, per exemple, ha calgut ajustar-ne la durada i els continguts i proposar activitats diverses d'interacció amb els estudiants, per resoldre els seus dubtes. De forma anàloga, les activitats d'avaluació han de tenir una naturalesa particular que integri el propòsit formatiu de tot procés d'avaluació continuada -això és, una avaluació orientada a l'aprenentatge- i les peculiaritats de l'aprenentatge en línia. Disposar d'aprenentatges valuosos respecte a com ha funcionat l'avaluació fins al moment pot resultar útil tant per no replicar pràctiques ineficaces, com per aprendre de les pràctiques d'èxit.

L'avaluació per a l'aprenentatge té un propòsit formatiu: guiar els processos d'aprenentatge i millorar els resultats d'aprenentatge. Una de les característiques clau d'una bona pràctica d'avaluació és el rol actiu dels estudiants a l'activitat d'avaluació (Cano et al., 2020, p. 60).

A més a més, l'autoregulació de l'aprenentatge és rellevant quan considerem les habilitats d'aprenentatge al llarg de la vida, i és per això que l'educació hauria de contribuir a desenvolupar-les (Zimmerman, 2002). L'autoregulació fa referència als pensaments autogenerats, sentiments i comportaments orientats a la consecució d'objectius, i s'entén com un procés cíclic, compost per tres fases: planificació, realització o execució i reflexió (Zimmerman, 2001).

La literatura sobre l'autoregulació de l'aprenentatge destaca el valor de la presència d'altres, on la interacció amb el professorat i els seus parells permet a l'estudiant internalitzar el procés autoregulador (Panadero et al., 2016). És aleshores que l'avaluació entre parells té importància. El peer feedback és una de les pràctiques d'avaluació entre parells, és a dir, una pràctica que implica un acord entre individus d'estatus similar, on es valoren determinats aspectes del resultat d'un procés d'aprenentatge. Per aquest motiu, els estudiants que participen en aquesta experiència també assumeixen el rol d'avaluadors per valorar la qualitat de la mateixa en d'altres grups.

Específicament, el feedback s'entén com una acció, mitjançant la qual l'estudiant dona sentit als comentaris que rep sobre el procés d'aprenentatge i els utilitza per millorar-lo (Nicol, 2020). El feedback així concebut es coneix com a sostenible o uptake (Carless i Boud, 2018). En aquest sentit, el feedback hauria de facilitar l'autoregulació de l'aprenentatge (Nicol i Macfarlane-Dick, 2006). A més a més, tal com aporten Muñoz i Lluch (2021), l'avaluació entre iguals en entorns virtuals d'aprenentatge, sempre i quan no es redueixi a assignar-hi una nota quantitativa, reforça la cooperació entre estudiants i el sentiment de comunitat d'aprenentatge, a més que n'estimula l'aprenentatge autoregulat, la motivació i el rendiment (Boud et al., 2018).

Amb tot, es té present que l'aprenentatge cooperatiu és una estratègia metodològica que dona resposta al desenvolupament de la competència tranversal de treball en equip de l'alumnat; és a dir, ajuda a desenvolupar la capacitat de col·laborar amb els altres i de contribuir a un projecte comú. Igualment,

\footnotetext{
${ }^{1}$ El Consell de Govern de la Universitat de Barcelona va aprovar el 10 d'abril de 2008 el document Les competències transversals a la Universitat de Barcelona, en el qual s'acorden les competències transversals comunes següents: compromís ètic, capacitat d'aprenentatge i responsabilitat, treball en equip, capacitat creativa i emprenedora, sostenibilitat i capacitat comunicativa.
} 
afavoreix la capacitat de col-laborar en equips interdisciplinaris i en equips multiculturals (Universitat de Barcelona, 2008). Aquesta competència s'identifica també en el Marc competencial del perfil innovador a les administracions públiques (Escola d'Administració Pública de Catalunya, 2020), en el qual s'indica que per aconseguir la innovació la persona ha d'estar orientada a l'acció, l'equip ha de ser cooperatiu i l'organització ha de ser sostenible. A més, en aquest marc competencial també s'identifica i s'hi descriuen vuit capacitats bàsiques necessàries per afrontar la innovació en el sector públic: autoorganització, aprenentatge autònom, creativitat, comunicació, treball en equip, fer xarxa, captar tendències i gestionar riscos.

En aquest sentit, al llarg de l'assignatura a la qual es refereix l'experiència que es presenta, els estudiants han de desenvolupar una tasca complexa, la qual serà treballada en petit grup. En parlar de tasca complexa ens referim a tasques que impliquen l'activació dels coneixements i la gestió de diferents tipus de continguts disciplinaris i l'execució de diferents competències (Monereo, 2003). Segons Trujillo (2008), una tasca complexa és aquella que integra diferents activitats o bé que es pot dividir en diferents fases. Altres característiques d'una tasca complexa són no tenir una única solució, requerir anàlisi crítica, raonament i integrar diferents tipus de coneixement. D'aquesta manera, l'alumnat podrà integrar el feedback rebut en una versió posterior, i això li permetrà poder transferir aquests aprenentatges a d'altres activitats $\mathrm{i} / \mathrm{o}$ assignatures.

El fet que els estudiants puguin assumir tant el rol d'executor com el rol d'avaluador comporta una implicació activa, perquè l'avaluació entre iguals representa processos reflexius i valoratius, també descriptius i analítics, sobre els elements que incideixen en la millora dels aprenentatges. Aquest procés té un propòsit formador en sí mateix perquè no només pretén que s'identifiquin les dificultats, sinó que serveix per comprendre'n les causes i prendre decisions en coherència (Sanmartí, 2007).

\section{Incorporació del feedback sostenible en el disseny d'activitats d'avaluació}

Partint dels plantejaments teòrics exposats en l'apartat primer, s'ha plantejat una investigació que estudia, en cinc titulacions diferents (Farmàcia, Arqueologia, Gestió i Administració Pública, Enginyeria Informàtica i Formació inicial de mestres), els efectes de les tecnologies digitals de monitorització sobre l'autoregulació de l'aprenentatge. Durant el curs 2020-2021 s'ha dissenyat i aplicat una seqüència d'avaluació entre iguals a les cinc titulacions, basada en el model cíclic de tres fases de l'autoregulació de l'aprenentatge de Zimmerman (2001). La contribució que es descriu a continuació es refereix específicament a l'experiència desenvolupada a la Facultat de Dret, en el marc de l'assignatura Economia Política del grau de Gestió i Administració Pública.

Per construir aquesta seqüència, s'ha dut a terme una revisió sistemàtica de la literatura, l'anàlisi de propostes pedagògiques prèvies, reunions amb l'equip de treball del projecte, a banda de l'aplicació del codi de bones pràctiques i del compliment dels principis de la seqüència RRI. En aquest disseny preliminar, les funcionalitats del Moodle que s'han fet servir, en funció de les fases d'autoregulació de l'aprenentatge, són el Fòrum (per compartir qualsevol dubte durant el procés sobre la planificació o execució de la tasca), la Wiki (per a la gestió del treball cooperatiu), l'eina Taller (per a la gestió de l'avaluació entre iguals) i la Tasca (per adjuntar la versió definitiva del treball amb una reflexió sobre com s'ha enriquit el seu procés d'aprenentatge i quins seran els aprenentatges que aplicaran en altres tasques o, fins i tot, assignatures).

Amb tot, l'objectiu d'aquesta contribució consisteix a presentar el disseny de la seqüència didàctica d'una tasca complexa d'aprenentatge cooperatiu i d'avaluació entre iguals, desenvolupada al Campus Virtual de la Universitat de Barcelona, per promoure l'autoregulació de l'aprenentatge, component clau de la competència d'aprendre a aprendre. 
Convé recalcar que el disseny de la seqüència d'intervenció d'avaluació entre iguals està sent sotmesa a una revisió per experts i pels propis participants (professorat i alumnat) a fi d'aplicar-hi millores i ajustarse a les oportunitats i limitacions plantejades.

L'assignatura Economia Política del grau de Gestió i Administració Pública és una assignatura de formació bàsica de sis crèdits, que s'imparteix en el segon semestre de primer curs del grau. Aquesta dada és rellevant perquè es tracta d'un alumnat encara molt jove, a qui cal acompanyar en el seu aprenentatge de manera més intensa que si fos de cursos més avançats.

Específicament, els resultats d'aprenentatge relacionats amb la competència d'aprendre a aprendre són els següents:

- Desenvolupar una actitud positiva i responsable envers l'aprenentatge.

- Implicar-se activament a comprendre i assimilar els aprenentatges proposats pel professorat.

- Dur a terme les tasques en el temps previst, seguint les pautes i les indicacions del professorat.

- Utilitzar les fonts d'informació proposades pel professorat.

- Detectar llacunes de formació i demanar ajut per resoldre-les quan sigui necessari.

- Identificar els aprenentatges assolits i saber-los comunicar.

A banda d'algunes proves tipus test de validació dels continguts que es tracten al llarg del curs, que tenen un pes en l'avaluació, es van dissenyar dues activitats d'avaluació continuada que requerien el desenvolupament d'un tema proposat, des d'una perspectiva aplicada. La primera activitat es va programar en acabar el primer bloc temàtic (temes 1-5) i la segona activitat en acabar el darrer bloc temàtic (temes 69). Les dues activitats consistien en una mateixa dinàmica de treball, que es descriu a continuació, i es realitzaven en grups estables, creats a l'inici del curs. Amb relació a la creació dels grups, l'única condició preestablerta era que fossin de cinc persones i els mateixos estudiants decidien amb qui formaven grup. Es van formar 12 grups de treball.

Per a cadascuna de les activitats es van definir tres temes relacionats amb els continguts del bloc temàtic que es volia avaluar. Per tant, cada tema era assignat a quatre grups. Cada grup havia de desenvolupar de manera col-laborativa entre els membres del grup el tema que li havia estat assignat, tot fent ús dels materials facilitats i seguint unes indicacions força precises.

El desenvolupament de l'activitat s'articula a través de les fases següents:

Fase 1. Organització per part de la docent.

En aquesta fase la docent planifica les passes necessàries per al desenvolupament de l'activitat:

- Distribueix els grups en dues categories: grups líders (GL, en endavant) i grups avaluadors (GA, en endavant), i els assigna rols diferents. Els grups líders han de preparar la primera versió del tema que els correspongui desenvolupar, reben feedback dels grups avaluadors $i$ han d'acabar redactant la versió final del tema, tot integrant el feedback rebut. Els grups avaluadors intervenen per valorar la primera versió elaborada pel grup líder que se'ls ha assignat i emeten un informe de feedback. Es preveu que els grups que són líders en la primera activitat d'avaluació passen a ser avaluadors en la segona activitat, i viceversa.

- Defineix els temes de treball, i identifica per a cada tema els materials de lectura necessaris. A més, estableix les consideracions que s'han de seguir per al desenvolupament de l'activitat.

- Proposa la distribució dels temes entre els grups líders i avaluadors. Cada tema és treballat per dues parelles de grup líder + grup avaluador. Cada parella prepara una proposta de desenvolupament del tema assignat, de manera que en acabar el procés es disposa de dues versions per a cada tema proposat.

- Facilita els criteris d'avaluació per valorar la tasca dels grups líder d'una banda i la dels grups avaluadors de l'altra. Aquests criteris són compartits amb l'alumnat per tal de comprendre'ls i integrar-los. 
- Per a cada grup líder habilita una activitat Wiki en l'espai del campus virtual destinat a l'activitat. Cada Wiki només és accessible als membres del grup que hi han de treballar. Els membres del grup han d'anar creant, a partir de les seves intervencions, una proposta de redactat per donar resposta a les diferents dimensions del tema que se'ls ha assignat. S'estableix la necessitat de fer servir la Wiki per construir la resposta perquè permet fer el seguiment de la intervenció de cada membre del grup.

- Organitza l'eina taller del campus virtual per a la fase 3: feedback de la resta de grups. Cada membre dels GL ha de penjar en el taller la versió inicial en què ha treballat per tal que pugui rebre feedback de l'estudiant avaluador que se li assigni. En el taller la docent habilita un formulari d'avaluació i estableix els criteris que s'han de tenir en compte per redactar un feedback de qualitat.

- Estableix el calendari de treball per a cadascuna de les activitats, definint els terminis de què disposen els grups líders i els grups avaluadors per fer les tasques respectives.

- Crea un fòrum de comunicació amb l'alumnat al campus virtual, per resoldre les qüestions que puguin anar sorgint al llarg del procés o enviar els recordatoris que cregui necessaris.

Fase 2. Preparació de la primera versió per part dels grups líders

- El grup líder disposa de cinc dies per elaborar de manera col·laborativa la primera versió.

- Els membres del grup han d'acordar com s'organitzen per treballar els materials facilitats i han de consensuar l'estructura del tema.

- Des de la Wiki tots els membres del grup han d'introduir les seves intervencions i proposar millores sobre les intervencions dels companys, fins arribar a consensuar un redactat final per a la primera versió de la tasca.

- Cada membre del grup líder ha de penjar al taller la primera versió de la tasca en què ha participat.

Fase 3. Feedback dels grups avaluadors

- Cada estudiant dels grups avaluadors valora des del taller la versió que ha rebut. Escriu les seves apreciacions en els camps habilitats i fa propostes de millora, d'acord amb les indicacions.

- Disposa de dos dies per fer les seves aportacions.

Fase 4. Redacció de la versió final

- Cada membre del grup líder analitza els informes individuals que li hagin arribat i identifica les millores que consideri oportú introduir en la versió inicial.

- Els membres del grup líder debaten entre ells sobre l'oportunitat d'introduir les diferents propostes de millora i es distribueixen les responsabilitats per introduir-les.

- En el termini de tres dies presenten la versió definitiva, que es mostra al conjunt de l'alumnat.

- Cada membre del grup líder lliura a la docent un breu informe de reflexió (relat de canvis) sobre el procediment i d'avaluació dels companys de grup, mitjançant el formulari que facilita la docent.

Fase 5. Avaluació de l'alumnat

Un cop acabades les versions dels estudiants la docent fa l'avaluació dels grups i convoca una sessió per comentar els resultats.

El procés es repeteix al final del curs, per desenvolupar tres temes corresponents als blocs temàtics restants. Els que han estat grups líders en el primer exercici d'avaluació passen a ser grups avaluadors en el segon.

\subsection{Característiques de l'avaluació de les activitats}

En aquest apartat es fa referència a les orientacions i als criteris d'avaluació que es van facilitar a l'alumnat. En primer lloc es recullen les indicacions adreçades als grups líder (GL) i a continuació les indicacions adreçades als grups avaluadors (GA). 


\section{Avaluació dels grups líder (GL)}

La puntuació global de l'activitat per a cada estudiant membre d'un GL és de 1,5 punts sobre 10, que s'assignen en base a la valoració de les 3 evidències següents:

1. Versió final generada (mateixa qualificació per a tots els membres del grup): 0,5 punts.

2. Aportacions individuals a la Wiki del grup: 0,5 punts.

3. Informe final de reflexió sobre el feedback rebut i incorporat (individual): 0,5 punts.

Tot seguit es descriuen els criteris d'avaluació del desenvolupament de la pregunta. Aquests cinc criteris són compartits amb l'alumnat per tal que els comprengui i els integri per assolir una tasca de qualitat i un bon aprenentatge.

Criteri 1:

Estructura ordenada, de manera que conté una primera part introductòria, en la qual s'enuncien els aspectes que s'abordaran; una segona part de desenvolupament d'aquests aspectes (més extensa) i una tercera part, amb les principals conclusions o reflexions finals.

Criteri 2:

Correcció pel que fa als diferents aspectes de l'expressió escrita (ortografia, sintaxi, lèxic)

Criteri 3:

Referència explícita i precisa als continguts de l'assignatura relacionats, de manera que s'evidenciï un nivell de coneixement i comprensió suficient.

Criteri 4:

Referència explícita i significativa als continguts de les fonts consultades que considereu més rellevants.

Criteri 5:

Seguiment del procediment establert i compliment dels terminis de lliurament.

\section{Avaluació dels grups avaluadors (GA)}

Cada membre d'un GA ha d'oferir un feedback qualitatiu adreçat directament al company/a assignat des de l'eina taller. La finalitat és que el GL pugui introduir millores en la versió final a partir del feedback rebut i millorar-ne la seva qualitat.

La puntuació global del feedback que aporta cada membre d'un GA és també de $\mathbf{1 , 5}$ punts sobre 10, que s'assignen en base als cinc criteris d'avaluació següents:

1. S'avalua la tasca tenint en compte l'objectiu de la tasca i els criteris d'avaluació ja enunciats per als GL.

2. S'ofereix una valoració constructiva. Els comentaris s'adrecen tant als punts forts com als punts febles (aspectes a millorar) de la tasca avaluada.

3. S'ofereix una valoració justificada. S'argumenta per què quelcom està bé i què es pot millorar.

4. S'ofereixen suggeriments concrets per millorar els punts febles assenyalats en el desenvolupament de la pregunta.

5. S'ofereixen suggeriments de millora per a futures tasques i processos d'aprenentatge.

A continuació, presentem un exemple del feedback ofert per un GA, a mode d'il·lustració: 
"L'activitat duta a terme, en relació amb els continguts de l'assignatura que estan presents a la pregunta a resoldre, consta de les definicions d'elasticitat-renda i dels tipus de béns que existeixen, això és un punt fort, ja que és correcta l'explicació dels continguts fonamentals de l'exercici perquè sigui més entenedor i això demostra que tenen els coneixements d'aquests temes de l'assignatura. Però en relació amb el contingut que demana l'activitat no s'assoleix el que es demana pel fet que no donen resposta a la pregunta que es fa, no reflexionen sobre les conseqüències en el comportament dels consumidors i tampoc plantegen els diferents escenaris en funció de si la variació del nivell d'ingressos de les famílies ha estat favorable o desfavorable. Aquest és un punt feble que cal desenvolupar molt més amb exemples i fent una cerca intensiva dels diferents casos de les famílies (hi ha un document en els materials recomanats per la professora "(Primer) impacto de la crisis de la COVID-19 en las familias atendidas por Cáritas Diocesana de Barcelona" que és interessant i podria ser molt útil) tot i també fent una reflexió més completa i extensa dels continguts."

Igualment recollim tot seguit la taula de reflexió (Taula 1) elaborada per una estudiant d'un GL com a informe final de reflexió arran del feedback rebut:

\begin{tabular}{|c|c|}
\hline $\begin{array}{l}\text { Què m'ha dit el meu company/a } \\
\text { en el feedback? }\end{array}$ & $\begin{array}{l}\text { Punts forts: } \\
\text { Pel que fa al primer aspecte, l'avaluador ens informa que l'informe està molt } \\
\text { ben estructurat i ordenat, ja que, té 'una introducció ben elaborada on } \\
\text { expliquen el tema a tractar al llarg de l'informe' i pel que fa al } \\
\text { desenvolupament 'està ben elaborat i desenvolupen el tema més extensament } \\
\text { i donen resposta al tema a tractar'. Llavors, aquesta estructura l'acaba } \\
\text { valorant dient-nos que la conclusió està ben plantejada i relacionada amb el } \\
\text { tema, com a punt fort. } \\
\text { Un altre punt fort en aquesta pregunta és sobre la comprensió del tema, on } \\
\text { l'avaluador en l'aspecte tres ens comenta que hi ha continguts que es } \\
\text { relacionen molt bé amb el tema, i que demostren que hem assolit un bon } \\
\text { coneixement amb relació al tema. } \\
\text { Seguint amb un altre punt fort, en aquest cas, les fonts consultades, } \\
\text { l'avaluador ens diu que es nota que hem aprofitat de manera important la } \\
\text { informació de les tres pàgines disponibles en els materials (afegir que també } \\
\text { hem inclòs d'altres a part del Campus). } \\
\text { Un altre punt fort es troba amb l'aspecte } 5 \text {, on ens diu que hem seguit el } \\
\text { procediment establert, ja que, donem una resposta de manera efectiva i } \\
\text { completa a la pregunta plantejada. } \\
\text { Punts febles: } \\
\text { En l'estructura, però, també tenim punts febles, com són, la manca dels } \\
\text { objectius, enquè falten ser més clars (1r apartat). } \\
\text { Al segon aspecte, ens puntua de forma forta que hi ha una expressió escrita } \\
\text { 'bastant acceptable' i amb coherència, però que pot dificultar la comprensió } \\
\text { del text, ja que, hi hafaltes d'ortografia i alguns errors gramaticals, per } \\
\text { aquesta raó està marcat com a punt feble. }\end{array}$ \\
\hline $\begin{array}{l}\text { Valoració del feedback rebut: } \\
\text { - Estic d'acord amb les } \\
\text { aportacions del meu } \\
\text { company/a? } \\
\text { - Em proposa millores concretes } \\
\text { per incorporar al document } \\
\text { final? } \\
\text { - És possible introduir els canvis } \\
\text { en el document final? }\end{array}$ & $\begin{array}{l}\text { Estic totalment d'acord amb les aportacions del meu company avaluador, ja } \\
\text { que, aspectes com els objectius són molt importants en un desenvolupament } \\
\text { introductiu, i aportacions com aquestes que ens han comentat, ens han fet } \\
\text { estar d'acord amb els avaluadors. } \\
\text { L'avaluador, ens proposa millores, com la introducció d'uns objectius més } \\
\text { clars i la millora de l'ortografia i en l'expressió escrita, a part, d'introduir una } \\
\text { petita introducció sobre què és la balança de pagaments. } \\
\text { A partir de les propostes de l'avaluador, ha sigut possible millorar els } \\
\text { objectius i totes les faltes ortogràfiques i d'expressió escrites que hem } \\
\text { detectat en el document. }\end{array}$ \\
\hline
\end{tabular}




\begin{tabular}{|l|l|}
\hline $\begin{array}{l}\text { Quin procés he seguit per tal } \\
\text { d'integrar el feedback dels meu } \\
\text { company/a? (quines accions he } \\
\text { fet i per què) }\end{array}$ & $\begin{array}{l}\text { En rebre el feedback del meu company, vaig llegir-lo vàries vegades. } \\
\text { Seguidament vaig rellegir vàries vegades també el nostre document principal, } \\
\text { per finalment fer una comparació amb el feedback i comentar-los als meus } \\
\text { companys quines millores hauríem d'introduir a partir de les aportacions de } \\
\text { l'avaluador. }\end{array}$ \\
\hline $\begin{array}{l}\text { Quins canvis hem fet com a grup } \\
\text { a partir del feedback rebut? Per } \\
\text { què? }\end{array}$ & $\begin{array}{l}\text { Després que cadascun dels meus companys líders poséssim en comú les } \\
\text { aportacions dels diferents avaluadors, en què en moltes coincidien, i } \\
\text { d'aquesta manera ens hem pogut decidir d'una manera més senzilla entre } \\
\text { nosaltres a l'hora d'introduir els canvis, hem introduit canvis gramaticals i } \\
\text { d'expressió escrita, una millor definició de l'objectiu i la reducció dels } \\
\text { caràcters que ens demanaven els avaluadors com a punt feble, perquè, pugui } \\
\text { ser més comprensible el nostre desenvolupament a la pregunta plantejada, ja } \\
\text { que, les aportacions eren molt eficaces per poder aconseguir un } \\
\text { desenvolupament molt correcte. }\end{array}$ \\
\hline $\begin{array}{l}\text { Quin procés hem seguit per } \\
\text { poder fer aquests canvis? Per } \\
\text { què? }\end{array}$ & $\begin{array}{l}\text { Entre tots els membres del grup, a través de diferents reunions de manera } \\
\text { telemàtica, hem pogut posar en comú els diferents feedbacks dels diferents } \\
\text { avaluadors, per poder avaluar-los entre tots i treure les màximes millores } \\
\text { possibles dels diferents feedbacks. On molts aspectes dels diferents } \\
\text { avaluadors coincidien (com, per exemple, la millora de l'ortografia), cosa } \\
\text { que ens han facilitat introduir els canvis i posar-nos d'acord de forma més } \\
\text { senzilla. També ens hem posat d'acord de quin membre feia el canvi que } \\
\text { millor se li podia donar a la Wiki, després de decidir els canvis entre tots, per } \\
\text { millorar la qualitat de la nostra feina feta. }\end{array}$ \\
\hline
\end{tabular}

Taula 1: Exemple d'informe final de reflexió després de reflexionar i integrar el feedback rebut

\section{Valoració de l'experiència i propostes de millora}

Arran de l'experiència descrita d'una tasca complexa d'aprenentatge cooperatiu i d'avaluació entre iguals per promoure l'autoregulació de l'aprenentatge, es van poder identificar algunes de les dificultats que va percebre i compartir l'alumnat participant de l'assignatura:

1. Les indicacions facilitades per desenvolupar l'activitat i els criteris d'avaluació estan recollides en diversos documents que contenen força informació.

2. Es tracta d'una activitat col-laborativa que requereix que cada estudiant realitzi la seva part en el termini assignat.

3. Els terminis són relativament breus i si algú no els compleix es veu compromès el desenvolupament de la tasca.

4. L'alumnat de primer curs, en general, té poca experiència en l'ús de les eines necessàries (Wiki i taller) i pot ser que tingui dificultat per entendre què se li demana.

5. Els criteris d'avaluació han de ser comprensibles per a l'alumnat, per tal que pugui integrar-los. Segurament, la preparació de rúbriques tant per als GA com per als GL podria facilitar l'avaluació i contribuir a la millora dels resultats.

Podem concloure, doncs, que es tracta d'una activitat exigent que, més enllà de les dificultats pròpies de la matèria -vinculades al desenvolupament de les competències específiques de l'assignatura-, requereix un alumnat implicat $\mathrm{i}$ atent $\mathrm{a}$ les indicacions que haurà de complir de manera puntual.

També esdevé molt necessari que el professorat segueixi de prop la dinàmica de cadascun dels grups i pugui intervenir en qualsevol moment per fer recordatoris i resoldre dubtes. Aquest aspecte haurà de ser considerat per millorar la seqüència d'intervenció, atenent que l'objectiu últim recau a enfortir la seva 
capacitat autoreguladora de l'aprenentatge. El fòrum habilitat ha de contribuir a fer possible una comunicació fluïda. Cal ser conscient, però, que un determinat percentatge de l'alumnat no seguirà l'activitat com caldria i que cal preveure solucions per reduir, tant com es pugui, l'afectació sobre els companys.

Més enllà de les dificultats concretes detectades, aquesta intervenció d'aprenentatge cooperatiu i d'avaluació entre iguals en el desenvolupament d'una tasca complexa en el camp de coneixement de Gestió i Administració Pública està sustentada teòricament i sotmesa a un procés de revisió i millora abans de la implementació a partir del proper curs 2021-2022.

El disseny de la seqüència, les activitats i els recursos que formen part de la intervenció, s'ha fonamentat en el procés cíclic d'autoregulació de l'aprenentatge (Zimmerman, 2001, 2002). Alhora, per a cadascuna de les fases del cicle, s'ha considerat la importància que l'alumnat s'apropiï dels criteris d'avaluació i que pugui reflexionar sobre com impactaran els comentaris de futur (feed-forward) (Nicol i MacFarlane-Dick, 2006). El disseny de la seqüència cerca alhora l'aprenentatge cooperatiu, sustentat en la tecnologia, utilitzada com a suport, aporti un valor afegit a l'experiència (Gros i Cano, 2021).

En endavant, resultarà interessant estudiar els reptes que obre aquest disseny sobre els efectes en el desenvolupament de l'autoregulació de l'aprenentatge i l'autonomia de l'alumnat, així com en el seu aprenentatge cooperatiu. A banda, convindrà estudiar la percepció i atribució d'aprenentatge per part de l'alumnat participant.

\section{Referències}

Boud, D., Ajjawi, R., Dawson, P., Tai, J. (Eds.) (2018) Developing Evaluative Judgment in Higher Education. Assessment for Knowing and Producing Quality Work. Routledge.

Cano, E., Pons-Seguí, L., Ion, G. (2020) The impact of peer feedback on student teachers' assessment literacy. A: P. Baughan (Ed.). On Your Marks: Learner-focused Feedback Literacy (pp. 60-71). AdvanceHE.

Carless, D., Boud, D. (2018) The development of student feedback literacy: enabling uptake of feedback. Assessment and Evaluation in Higher Education, 43(8), pp. 1315-1325.

Gros, B., Cano, E. (2021) Procesos de feedback para fomentar la autorregulación con soporte tecnológico en la educación superior: Revisión sistemática. RIED. Revista Iberoamericana de Educación a Distancia, 24(2), pp. 107125.

Escola d'Administració Pública de Catalunya (2020) Marc competencial del perfil innovador a les administracions públiques. http://eapc.gencat.cat/ca/detalls/Noticia/06 marc-competencial-del-perifil-innovador

Monereo, C. (2003) La evaluación del conocimiento estratégico a través de tareas auténticas. Pensamiento Educativo, Revista de Investigación Latinoamericana (PEL), 32(1), pp. 71-89.

Muñoz, J.L., Lluch, L. (2021) Evaluación de los aprendizajes de los estudiantes universitarios en una realidad confinada. Revista Iberoamericana de la Evaluación educativa, 14(2), pp. 37-50.

Nicol, D. (2020) The power of internal feedback: exploiting natural comparison processes. Assessment and Evaluation in Higher Education, 46(5), pp. 756-778.

Nicol, D.J., Macfarlane-Dick, D. (2006) Formative assessment and self-regulated learning: A model and seven principles of good feedback practice. Studies in Higher Education, 31(2), pp. 199-218. 
Panadero, E., Jonsson, A., Strijbos, J.W. (2016) Scaffolding self-regulated learning through self-assessment and peer assessment: Guidelines for classroom implementation. A: D. Laveault, L. Allal (Eds.). Assessment for Learning: Meeting the challenge of implementation. Springer International Publishing, New York.

Sanmartí, N. (2007) Diez ideas claves. Evaluar para aprender. Graó, Barcelona.

Trujillo, F. (2008) Competencia en comunicación lingüística nunha europa plurilingüe e pluricultural. Ensinanza de linguas no contexto europeo: tendencias e propostas. https://docplayer.es/52379208-Competencia-en-comunicacionlinguistica-nunha-europa-plurilingue-e-pluricultural.html

Universitat de Barcelona (2008) Competències transversals de la Universitat de Barcelona. Normatives i documents. http://www.ub.edu/cubac/sites/default/files/ct_de_la_universitat_de barcelona_1.pdf

Zimmerman, B.J. (2001) Theories of self-regulated learning and academic achievement: An overview and analysis. A: B.J. Zimmerman, D.H. Schunk (Eds.). Self-regulated Learning and Academic Achievement: Theoretical Perspectives (pp. 1-37). Lawrence Erlbaum, London.

Zimmerman, B.J. (2002) Becoming a self-regulated learner: An overview. Theory into practice, 41(2), pp. 64-70. 